\title{
Arbor
}

\section{Un mundo sin límites}

\author{
Joaquín $M^{a}$ Córdoba
}

Arbor CLXXX, 711-712 (Marzo-Abril 2005), 553-558 pp.

A comienzos del siglo XVI, las nuevas ediciones del Atlas de Ptolomeo publicadas en Roma o Venecia solían incluir un mapamundi modificado sin cesar $^{1}$, a medida que descubridores y navegantes alcanzaban nuevos y antes desconocidos horizontes. La temprana circunnavegación de Magallanes y Elcano (1519-1522) confirmaba con su esferidad, que el mundo no tenía límites. Durante aquel siglo magnífico, la literatura española de viajes al Oriente Próximo islámico tenía que ser menos señalada. La casi perenne guerra contra el Imperio Otomano, señor de una buena parte de las costas mediterráneas, y sobre todo la empresa de América y los viajes de exploración y conquista que aquella demandaba, orientaron el rumbo de la mayoría de los aventureros españoles y sus libros por las rutas del Poniente, aunque desde esa misma América se lanzarían pronto por el Pacífico y el Lejano Oriente ${ }^{2}$. Por el contrario, los portugueses insistieron especialmente en sus viajes por mar a la India, en los que levantaron planos y mapas magistrales -como refleja el Atlas de Lopo Homem ${ }^{3}$-, y en el curso de los cuales frecuentaron las costas de Arabia, Irán y el Golfo Pérsico ${ }^{4}$, aunque también por necesidad u obligación, algunos transitaran a veces las rutas terrestres por Mesopotamia, como siglos después harían los británicos. No obstante, viajeros españoles como el noble y peregrino Don Fadrique de Ribera, un aventurero titánico como Pedro Ordóñez de Ceballos, y un sabio y valiente religioso jesuita como el padre Páez, sumarían páginas increíbles aportadas por la cultura española a la historia de la literatura de viajes a Oriente Próximo y a su redescubrimiento.

Durante los primeros años del siglo, el pacífico reinado del sultán Bayaceto II hizo que la región viviera en paz. Pero su sucesor Selim I reanudaría las conquistas, arrebatándole Armenia al sha Ismail y conquistando además entre 1515 y 1517, los reinos mamelucos de Siria, 
Palestina y Egipto que habían ayudado al persa. Desde ese instante, todas las rutas comerciales de Oriente estarían en manos turcas, y el comercio occidental empezó a buscar alternativas para burlar las tasas y recargos impuestos por los otomanos. No obstante, un cierto comercio seguiría perviviendo siempre, lo mismo que las peregrinaciones, aunque éstas decayeran en número y frecuencia, a tenor de la situación política. $\mathrm{Al}$ comenzar el siglo, los barcos venecianos dedicados al transporte de peregrinos hacían sólo un viaje anual a Tierra Santa, pero la frecuencia se triplicó a partir de 1520, reduciéndose de nuevo al mínimo anual tras el $1546^{5}$. Por Alejandría y Jaffa como puertos de entrada, muchos cristianos siguieron cumpliendo su soñada peregrinación, como fray Antonio de Lisboa y fray Diego de Mérida -que dejarían recuerdo manuscrito de sus viajes $^{6}-\mathrm{y}$, naturalmente, el más famoso de todos ellos, Don Fadrique Enríquez de Ribera, primero de los señalados viajeros españoles de este siglo, autor de un curioso relato que mereció sucesivas ediciones impresas. En 1523, no mucho después del viaje de Don Fadrique, un noble portugués llamado Don Antonio Tenreiro estuvo en Irán, acompañando la embajada de Don Balthasar Pessoa. A la muerte del sha, Tenreiro decidió peregrinar a Tierra Santa, cayendo en manos de los turcos. Liberado en El Cairo, volvió a Ormuz cruzando el desierto sirio-iraquí, y tras algunos años de servicio en aquella plaza, como portador de cartas para el rey de Portugal volvió en 1528 navegando por el Golfo Pérsico y el Eufrates, y tras visitar Bagdad cruzó de nuevo el desierto. Escritos con un estilo seco y conciso, los recuerdos de sus aventuras serían publicados en $1570^{7}$.

En los grandes océanos y mares de entonces, las órdenes de los contramaestres y pilotos se oían en portugués y español, pero la ruta atlántica e índica hacia la India era sobre todo empresa portuguesa. Desde Lisboa, buques y escuadras daban por el Atlántico la "volta grande", para provechar los vientos y las corrientes favorables, pasar el Cabo de Buena Esperanza ${ }^{8}$ y remontar luego por las costas de África, a uno otro lado de Madagascar, hasta coger los rumbos que desde Adén y las costas del Hadramaut les llevaran hasta Goa. Durante más de dos siglos, la Carrera de Indias costó numerosas tragedias y naufragios, recogidos en relatos que formaron un verdadero género literario, profusamente leído por su fácil circulación en cuadernillos y sueltos. Doce de ellos fueron luego reeditados por Bernardo Gomes de Brito, en su História Trágico-Marítima $(1735-1736)^{9}$. Pues bien, uno de los navegantes y aventureros inmersos en esta valerosa y arriesgada Carrera de Indias fue Fernao Mendes Pinto (150-1583), de cuya vida y aventuras podrían escribirse cien relatos ve- 


\section{Un mundo sin límites}

races. Entre 1537 y 1558 Fernao vivió, navegó y viajó por Oriente, conociendo Arabia, Etiopía, India, Malaca, Sumatra, Siam y las costas de China y Japón. Se desempeñó como marino, comerciante, aventurero y soldado. Cautivo muchas veces, esclavo vendido y liberado, jesuita un tiempo, retornó a Portugal el 22 de septiembre de 1558. Sin recibir la recompensa que creía merecer, quiso escribir el relato de sus viajes y aventuras, a lo que dedicó el resto de su vida. Admirado por Felipe II, que le protegió al final de sus días, cuando ya Portugal y España formaban una sóla nación, murió el 8 de julio de 1583. Su monumental Peregrinaçao, publicada en Lisboa en 1614, dedicada a Felipe II, sería traducida de inmediato al español por Francisco de Herrera Maldonado ${ }^{10}$. La gran popularidad que alcanzó entre nosotros viene avalada por sus sucesivas reediciones, y es que su persona y sus viajes alimentaron sin duda los sueños y las fantasías viajeras de otros aventureros españoles del siglo XVI, como Pedro Ordóñez de Ceballos.

Para la Europa del siglo XVI, Oriente parecía dramáticamente cercano, pues tras dominar paulatinamente toda la Península Balcánica, el Imperio Otomano aplastaba en 1526 al reino de Hungría en Mohács, catastrófica batalla en la que el joven monarca magiar, Luis II, pereció con lo mejor de su ejército ${ }^{11}$. Seis años después, los turcos llegaban a las puertas de Viena. El desastre centroeuropeo afectó profundamente a España - comprometida con Austria por el imperio de Carlos o la vinculación familiar después, con Felipe II-, que además vivía la amenazante presión otomana en el mar. Por eso, para los españoles del siglo XVI Oriente Próximo era el Imperio de los turcos, sus rivales en el Mediterráneo. Aunque la curiosidad sobre aquel mundo también contaba, como revela el famoso Viaje de Turquía, que además de contar las angustias y penalidades de los cautivos cristianos, evoca con tino las costumbres turcas más variadas y sitios admirables de su imperio, como los monasterios del Monte Athos y la misma Constantinopla ${ }^{12}$. O la Historia de los turcos de Vicente Roca, publicada en Madrid en 1556. Pero la amenaza era bien cierta. Todavía hoy, las costas levantinas y andaluzas aparecen jalonadas por unas sencillas torres de piedra, testimonio olvidado de un sistema siempre en guardia, para defensa y aviso de la población ante el frecuente ataque de piratas berberiscos y naves turcas.

Durante la segunda mitad del siglo se tëndría un respiro. El 7 de octubre de 1571, España encabezó la flota católica que derrotaría a los turcos en la célebre batalla de Lepanto ${ }^{13}$, freno decisivo a su poderío naval en el Mediterráneo. De resultas sin duda, el comercio y las comunicaciones se aligeraron durante un tiempo, y no es casual que en 1573 iniciara 
sus jornadas por Oriente el médico alemán Hans Leonhardt Rauwolf, que buscando el saber de medicinas y plantas viajó durante tres años por Siria y Mesopotamia. En la historia del redescubrimiento de las culturas antiguas hay que citar que, el 24 de octubre de 1574, tras cruzar el Éufrates en Faluya, Rauwolf visitó las ruinas Aqar Quf, restos impresionantes de una antigua zigurat casita, que como el hombre letrado y religioso que era, supuso restos de la famosa torre de Babilonia ${ }^{14}$.

Por aquellos años, en los corrales de comedia españoles se seguían obras como el auto y tragedia Nabucodonosor, de J. Álvarez (1562), La gran Semíramis, de Cristobal de Virués (1570) o la Tragedia de la destruición de Contstantinopla, de G. Lobo Lasso de la Vega $(1587)^{15}$, obras que aún teniendo a los clásicos o la Biblia como fuente para las leyendas más remotas, demuestran la curiosidad que la palabra "Oriente» seguía despertando en el público. Y pese a todos los pesares, viajeros y comerciantes europeos seguían entrando por las rutas de Oriente. Uno de los más singulares sería otro de los grandes viajeros españoles del siglo, $\mathrm{Pe}$ dro Ordóñez de Ceballos, que entre 1562 y 1602 estuvo viajando por todo el mundo y en Oriente, además del Mediterráneo Oriental, Palestina y el Mar Negro en su primera aventura, conoció Ormuz, Goa, Ceylán, Indochina, Macao y Cantón en otras de las muchas jornadas que a su propio decir totalizaron más de treinta mil leguas.

Con la unión de las coronas española y portuguesa en la cabeza de Felipe II, sin mengua del exquisito respeto que mostró siempre el rey con las susceptibilidades portuguesas, España se asomó también al Índico siguiendo la ruta de la Carrera de Indias lusa, y apoyó el imperio con medios, diplomacia y esfuerzos en la evangelización ${ }^{16}$. Y como el rey tenía ante sus ojos el mundo, cuando Abraham Ortelius le dedicó su Atlas, primero concebido con criterio uniforme ${ }^{17}$, tal vez se encendió entonces su deseo de entrar en contacto con el monarca cristiano de Etiopía, que sería el origen de otra gran aventura. Y gracias a ésta podemos recuperar hoy la memoria de otro de los grandes viajeros españoles de todos los tiempos, el jesuita Pedro Páez, natural de Olmeda de las Fuentes, en la provincia de Madrid, que junto al padre Antonio de Montserrat sufrió siete años de cautiverio en Arabia. Ambos fueron los primeros europeos conocidos que estuvieron -y lo contaron después- en Zofar, que cruzaron luego el corazón del Hadramaut y que vivieron en distintas ciudades de Yemen y Arabia, como Tarim, Qatna y Moka.

En 1596, el padre Páez y su compañero fueron liberados, gracias al empeño personal del mismo Felipe II. Devueltos ambos a Goa, pocos años después el jesuita madrileño podría empezar al fin su gran aventura vi- 


\section{Un mundo sin límites}

tal en Etiopía. Pero mientras este gigante de la historia del viaje a Oriente sufría sus aventuras, aquel siglo asombroso daba paso a los enredos diplomáticos inciados por dos singulares británicos, Robert y Anthony Sherley, embajadores y aventureros por Irán. En 1598, los dos hermanos llegaron a la corte del sha Abbás el Grande, al que animaron a buscar una alianza con los príncipes cristianos frente a Turquía ${ }^{16}$. Y con una embajada del sha, que partió de Irán el año 1599, además del embajador persa y Anthony Sherley llegaría a nuestro país el secretario de la misma, Uruch Beg, que convertido al catolicismo decidiría quedarse en España bajo el nombre de Don Juan de Persia. Para nosotros, las Relaciones que habría de publicar no mucho después ${ }^{17}$, son como un asombroso tornaviaje de la aventura española. Y es que verdaderamente, aquel siglo fue el de un mundo sin límites.

\section{Notas}

1. Allen, Ph. (1993) : Summa Atlas. El mundo visto por los cartógrafos (1482-1897). Salvat Ediciones Generales, S. A., Barcelona. Véanse laminas de Johan Ruysch, Jacous Pentius y hasta el magnífico y más tardío de Ortelius, en pp. 18-19, 26-27 y 36-39 respectivamente.

2 PRIETo, C. (1975) : El Océano Pacífico: navegantes españoles del siglo XVI. Alianza Editorial, S. A., Madrid.

3 Albuquerque, L. de y Marqués dos Santos, A. (1992): «Los cartógrafos portugueses», en ChANDEIGNe, M.(dir.) : Lisboa extramuros, 1415-1580. El descubrimiento del mundo por los navegantes portugueses. Alianza Editorial, S. A., Madrid, pp. 71-80.

4 Teyssier, P. (1992): en Chandeigne, M. (dir): op. cit., pp. 14-54.

5 Jones, J. R. (1998): Viajeros españoles a Tierra Santa (siglos XV y XVII). Miraguano Ediciones, S. A. - Ediciones Polifemo, Madrid, p. 80.

6 JoNES, J. R. (1998): op. cit., pp. 95-96.

7 Tenreiro, A. (1570): Itinerario de Antonio Tenrreyro da ordem de Christo, em que se contem como da India veo por terra a estos Reynos de Portugal. Impresso em Coimbra, em casa de Antonio de Maris.

8 Soler, I. (2004): Los mares náufragos. Acantilado, Barcelona, pp. 10-11.

9 Soler, I. (2004): op. cit., pp. 22-28. Entre los relatos y autores recogidos por Bernardo Gomes de Brito hay que señalar la persona de Diogo Couto, historiador, archivero y gran cronista del Asia portuguesa, muerto en Goa en 1616, muy crítico con el mal funcionamiento de la administración lusitana; también la de Joao Baptisa Lavanha, ingeniero naval y cosmógrafo, profesor de los reyes Felipe II, Felipe III y Felipe IV. Ninguno de los dos sufrió personalmente la experiencia del naufragio. Véanse pp. 22-23.

10 Sobre Fernao Mendes Pinto, su libro y las circunstancias de su vida es excelente el estudio introductorio del editor de la traducción española publicada en su día por Francisco Herrera Maldonado en 1620: MAHIEU, J. A. (ed.). (1982): Fernao Mendes Pinto. Las Peregrinaciones. Ediciones Alfaguara, S. A., Madrid. Véase dicha introducción y estudio sobre la biografía y el relato de Mendes Pinto en pp. XIII-XLIII. Igualmente hay que des- 
tacar el interesantísimo estudio de TRIAS Folch, L. (2003): La Peregrinación de Fernao Mendes Pinto, Editorial Síntesis, S. A., Madrid.

11 Como es bien sabido, la esposa del rey Luis era María de Habsburgo, hermana de Carlos V. Por lo demás, en la cultura húngara, la batalla de Mohács ha tenido un peso parecido al que la de Guadalete ha conservado en la española. Sobre la batalla y la política de la época, CsorBA, Cs., EstóK, J. y SALAmon K. (1999): Die illustrierte Geschichte Ungars. Magyar Könyuklub, Budapest, p. 67.

12 Una edición clásica es la de Solalinde, A. G. (ed.) (1965): Cristobal de Villalón. Viaje de Turquía. Espasa Calpe, S. A., Madrid. La tradicional atribución a Cristobal de Villalón fue cuestionada. Marcel Bataillon, por ejemplo, señalaba al famoso Andrés Laguna, médico y viajero notable como su verdadero autor. Véase DíEz-EcHARRI, E. y Roca FRANQUESA, J. Ma . (1972) : Historia de la literatura española e hispanoamericana. Aguilar, Madrid, pp. 341-342.

13 Kamen, H. (1997): Felipe de España. Siglo XXI de España Editores, S. A., Madrid, pp. 143-145.

14 Sievernich, G. y Budde, H. (eds.) (1989): Europa und der Orient, 800-1900. Bertelsmann Lexikon Verlag, Berlin, p. 473. El título de la obra de Leonhardt Rauwolf, publicada en Frankfurt en 1582, con una ortografía lógicamente muy distinta a la del alemán moderno, resulta de una largura y minuciosidad descriptiva asombrosa y ciertamente simpática: Aigentliche beschreibung der Raiss so er vor diser zeit gegen Auffgang inn die Morgenländer fürnemlich Syriam, Judaeam, Arabiam Mesopotamiam, Babyloniam, Assyriam, Armeniam, ec. nicht ohne geringe mühe unnd grosse gefahr selbs volbracht: neben vermeldung vil anderer setlzamer und denckwürdiger sachen die alle er auff solcher erkundiget gesehen und observiert hat.

15 Huerta Calvo, J. (dir.) (2003): Historia del Teatro Español. Vol. I.-- De la Edad Media a los Siglos de Oro. Editorial Gredos, S. A., Madrid. Sobre la tragedía La gran Semíramis, p. 491: sobre la obra de Lasso de la Vega, p. 497.

16 KAMEN, H. (1997): op. cit., pp. 256-259.

17 Ortelius fue el padre de la moderna cartografía. Su Atlas, dedicado a su rey Felipe II sería luego copiado durante mucho tiempo. Véase ALLEN, Ph. (1993): op. cit. pp. 3639. Vid. p. 36.

18 Ross, E. D. (ed.) (1933): Sir Anthony Sherley and his Persian Adventure. London.

19 Alonso Cortes, N. (ed.) (1946): Relaciones de Don Juan de Persia, Madrid. Véase también GIL, L. (1985): "Sobre el trasfondo de la embajada del sha Abbas I a los príncipes cristianos: contrapunto de las Relaciones de don Juan de Persia», Eclás. 27, n 89, pp. 343-377. 